\title{
Design and Development of Chitosan Beta-cyclodextrin based Nasal Mucoadhesive Microspheres of Clarithromycin
}

\author{
Subramanaian Rajarajan ${ }^{1, *}$, B Prakash Rao², S Selvamuthukumar ${ }^{1}$ \\ 'Department of Pharmacy, Faculty of Engineering and Technology, Annamalai University, Annamalai Nagar, Chidambaram, Tamil Nadu, INDIA. \\ 2Department of Pharmaceutical Technology, Karnataka College of Pharmacy, Bangalore, Karnataka, INDIA.
}

\begin{abstract}
Objectives: The present systematic research is to design, develop clarithromycin nasal mucoadhesive microspheres for the utilisation in respiratory tract infection as alternative route of drug delivery. Methods: Current study designed to formulate, evaluated by using chitosan, beta cyclodextrin with modified emulsion lyophilisation method. $2^{4}$ factorial design was used in optimization technique. Characterisation of prepared microspheres will be subjected for particle size and size distribution, drug entrapment study, in vitro drug diffusion studies and ex vivo mucoadhesion, surface morphology, zeta potential, infra-red radiation, differential scanning calorimetry, X-ray diffraction and stability studies. Results: The optimised formulation of predicted values of chitosan 0.604, Beta cylclodextrin 0.7633, Propeller Mixing Speed 9369 and Lyocycle temperatue of $-42.8^{\circ} \mathrm{C}$, Particle Size $14.06 \mu \mathrm{m}$, Entrapment efficiency $73.32 \%$, Mucoadhesion $81.03 \%$ and
\end{abstract}

Maximum drug release $80.56 \%$. Other finding results were satisfactory in control of quality attributes. Conclusion: Developed microspheres can be potential highlight on utilisation of clarithromycin as nasal drug delivery with beneficial as alternative dosage form for respiratory tract infections Key words: Clarithromycin, Mucoadhesive microspheres, $2^{4}$ Factorial Design, Nasal delivery, Beta cyclodextrin.

\section{Correspondence}

Mr. Subramanian Rajarajan

Department of Pharmacy, Faculty of Engineering and Technology, Annamalai University, Annamalai Nagar-608002, Chidambaram, Tamil Nadu, INDIA

Phone no: +91-9986197560

Email: pharmking@gmail.com

DOI: 10.5330/ijpi.2020.3.51

\section{INTRODUCTION}

The Recent study intranasal route been employed as a substitute of management for systemic action than the delivery of localised drugs. In the nasal cavity benefits of large surface area, quick absorption and fast onset of action and prevention of the first-pass metabolism. Moreover, the nasal cavity is convenient way of administration. ${ }^{1}$ This route is encouraging route for delivery of drugs comprising biopharmaceuticals. low absorption i.e. solubility of drugs can be enhanced in presence of absorption enhancers or increasing the drug residence time in the nasal cavity, besides that certain mucoadhesive polymers can help both purposes. $^{2}$

The mucoadhesive agents provide an assistance of amplified residence time and better vaccine efficacy. Potential absorption of vaccine formulations, in primary olfactory nerves of nasal cavity. ${ }^{3}$ To improve the mucoadhesion, bioadhesive agents can be used such as chitosans, ${ }^{4}$ thiomer $^{5}$ and alginate. ${ }^{6}$ Many reports of new specific formulations modification with formulated nasal microspheres were reported with melatonin, ${ }^{7}$ diltiazem hydrochloride, ${ }^{8}$ doxorubicin, ${ }^{9}$ Methotrexate ${ }^{10}$ and deferoxamine. ${ }^{11}$ Respiratory tract infections (RTI) remain the most common and significant problems in clinical medication. This infection arises with a simple knowledge of the pathophysiology of the respiratory tract and how immune defences relate with pathogens. ${ }^{12}$ RTI includes the upper and lower respiratory tract in the nose, sinuses, pharynx or larynx. Normally this includes nasal limitation, sore throat, tonsillitis, pharyngitis, laryngitis, sinusitis, otitis media and common cold. Mostly these infections are viral in types and in other chances are reason may be bacterial or fungal or helminthic in origin, but these are extremely fewer in public.
Clarithromycin is a macrolide antibiotic with biopharmaceutical classification system class II, causing in low oral bioavailability ${ }^{13}$ shorter biological $t_{1 / 2}(3-5 \mathrm{~h})$, which inspires development of mucoadhesive release drug delivery system. Effective utilisation of clarithromycin as a powder for inhalation to diminish the systemic acquaintance and advance in of progress the drug diffusivity into the viscous mucus. ${ }^{14}$ Based on the above sited reference information the formulations of nasal mucoadhesive microsphere will be an alternate formulation, as promising drug delivery for effective localized and systemic action. This current study described about design, formulation, evaluation and characterisation and Stabilities studies of nasal mucoadhesive microspheres of macrolide drug with suitable natural hydrophilic polymer materials composites.

\section{MATERIALS}

Clarithromycin, Chitosan (87\% deacetylated), Beta cyclodextrin, Liquid paraffin (light), purchased from Yarrow chem products., Mumbai; Span 80, Glacial acetic acid, Diethyl ether and Isopropyl alcohol purchased from Merck; All the other chemicals were used in the grade of analytical.

\section{METHODS}

\section{Preparation of Microspheres by Modified Emulsion - Lyophilisation method}

Clarithromycin $(\mathrm{CM})$ containing microspheres were prepared by modification of emulsion and solvent evaporation method. ${ }^{15}$ The microspheres preparation in three step process, in the first step solvent dispersed drug solution was mixed with previously aqueous reconstituted 
beta Cyclodextrin $(\beta C D)$ solutions was propelled until the removal of solvent from the drug solution. Chitosan solubilised in $0.1 \%$ acetic acid solution also kept aside. Then Chitosan solution was mixed with drug in $\beta C D$ solutions at different concentrations as per the design. The second step complete mix of drug, $\beta \mathrm{CD}$ and Chitosan solutions were drop wise poured into Light and heavy liquid paraffin mixed (50:50) in 0.1\% Span 80 liquid as dispersing medium. Mixing was followed by appropriate mixing speed of using T 25 digital Ultra-Turrax ${ }^{\circledR}$ dispersing instrument as per design. In third step, microsphere dispersion resulting solutions were filtered and microspheres were separated by repeated wash with n-hexane to dehydrate the microspheres, followed by freeze drying using Labconco Free Zone 4.5 Litre Bench top Freeze Dry System appropriately as per the design.

\section{Experimental design}

A $2^{4}$ factorial design with centre point value was considered in this model to optimise response variables. Statistical Design of experiments implemented by DESIGN EXPERT ${ }^{\circledast}$ trial version 9.0.2.0 (Stat-Ease Inc., Minneapolis, USA). Experiments performed for nine formulations. In this model factors are coded $(-1,+1$ and 0$)$ were considered for dependent variables polymer concentration (X1), enhancer concentration (X2), mixing Speed (X3) and freeze drying temperature (X4). Four Independent variables particle size (Y1), \% entrapment efficiency (Y2), mucoadhesion (Y3) and maximum drug release (Y4). 3D response surface graph are utilised to study of factor's interaction between the factor and responses. The factorial design parameters with respective formulations are drawn in Table $1 .{ }^{16-18}$

Analysis of ANOVA calculation with parameters of analysis results of R2: Coefficient of regression, SD: Standard deviation, CV: Coefficient of variation, SS: Sum of squares, DG: Degree of freedom, MS: Mean sum of squares, f: Fischer's ratio. These results of variance observations pooled to estimate of true error of variance.

\section{The percentage yield}

Microspheres were determined the percentage weight of the final dried product with respect to theoretical weight of $\mathrm{CM}$ microspheres were carried out.

\section{Drug Entrapment efficiency}

The amount of CM entrapped in microspheres by taking $10 \mathrm{mg}$ of CM to $10 \mathrm{~mL}$ containing phosphate buffer $\mathrm{pH} 6.2$ and methanol (9:1) solution. Above solution was filtered and centrifuged at $10000 \mathrm{rpm}$ for $5 \mathrm{~min}$ then resulting supernatant solution was determined for $\mathrm{CM}$ drug content by following the cited validated HPLC procedure, ${ }^{19,20}$ test samples were analysed using HPLC-UV chromatography (Agilent) with a binary pump, a vacuum degasser, an manual injector, a column oven and a UV detector, $20 \mu \mathrm{ml}$ of samples were injected onto the analytical column (Agilant Zorbax C8 150X 4.6 X $5 \mu \mathrm{m}$ ). The analysis was done isocratically with a flow rate of $1 \mathrm{ml} / \mathrm{min}$, at $40^{\circ} \mathrm{C}$ with mobile phase containing the methanol and $50 \mathrm{mM}$, phosphate buffer $(\mathrm{pH} 4)$ at a ratio of 60: 40. The 20 min total runtime was used $20 \mathrm{~min}$; CM detected subsequently at 10.34 min with wavelength of $210 \mathrm{~nm}$. The chromatographic data was analysed in the Ez chrome software. ${ }^{21}$

\section{Drug diffusion studies}

In vitro drug permeation test performed for $\mathrm{CM}$ microspheres with Franz diffusion cell of $140 \mathrm{ml}$ capacity. The semipermeable membrane molecular weight cut of $12-14 \mathrm{kDa}$ was mounted on mouth of the diffusion cell. The microsphere drug equivalent to $100 \mathrm{mg}$ taken in the donor compartment was incorporated in simulated nasal fluid, $(8.77 \mathrm{~g}$ sodium chloride, $2.98 \mathrm{~g}$ potassium chloride and $0.59 \mathrm{~g}$ calcium chloride with 1 litre). The receptor section was made with full volume capacity of phosphate buffer of $\mathrm{pH} 6.2$, similarly to that of $\mathrm{pH}$ range of nasal cavity and maintained at $37 \pm 0.5^{\circ} \mathrm{C}$. A magnetic stirrer was placed in the receptor compartment. $1 \mathrm{ml}$ sample was periodically withdrawn and substituted with same amount of buffer solution during 6 hr study. Drug content was determined by HPLC method as described in entrapment efficiency. ${ }^{22}$

Ex vivo drug permeation was performed by using a fresh slice $(\sim 2.5$ $\mathrm{cm}^{2}$ ) of sheep nasal mucosa was obtained from local slaughterhouse (Bangalore, India) as membrane to place on the mouth of the Franz diffusion cell instead of semipermeable membrane as like experimentation of in vitro drug diffusion study. The drug retained in goat nasal mucosa during drug release was adjusted for the calculation for optimal drug concentration determination by similar HPLC technique.

\section{Particle size and size distribution and Polydispersibility index}

The mean particle size of CM microspheres was performed by dynamic light scattering (Malvern Instruments, UK). Samples were dispersed in Milli Q water appropriately at $25.1^{\circ} \mathrm{C}$ with equilibration time is $70 \mathrm{Sec}$ with 8 attenuation. Polydispersibility index used to measure of broadness with molecular weight distribution.

\section{Zeta potential}

The surface potential of $\mathrm{CM}$ microspheres were performed by Electrophoretic light scattering technique to attain the electrophoretic mobility of microspheres in using a Zetasizer nano ZS (Malvern Instruments, UK).

Table 1: Summary of ANOVA and regression analysis for measured responses.

\begin{tabular}{ccccccccccccc}
\hline Responses & Model & $R^{2}$ & $\begin{array}{c}\text { Adjusted } \\
R^{2}\end{array}$ & SD & CV & SS & DG & MS & F-value & $\begin{array}{c}p \text {-value } \\
\text { Significance }\end{array}$ \\
\hline R1 & Linear & 0.9885 & 0.9770 & 0.1857 & 1.31 & 11.87 & 4 & 2.97 & 86.07 & 0.0004 & Significant \\
R2 & Linear & 0.9791 & 0.9582 & 0.5672 & 0.768 & 60.32 & 4 & 15.08 & 46.87 & 0.0013 & Significant \\
R3 & Linear & 0.9822 & 0.9644 & 1.11 & 1.36 & 272.22 & 4 & 68.05 & 55.17 & 0.0009 & Significant \\
R4 & Linear & 0.9833 & 0.9666 & 0.5545 & 0.684 & 72.46 & 4 & 18.12 & 58.92 & 0.0008 & Significant \\
\hline
\end{tabular}

R1: Particle Size, R2: Entrapment Efficiency, R3: Mucoadhesion, R4: Maximun Drug Release, ANOVA: Analysis of variance, R²: Coefficient of regression, $\mathrm{SD}$ : Standard deviation, CV: Coefficient of variation,

SS: Sum of squares, DG: Degree of freedom, MS: Mean sum of squares,

$\mathrm{f}=\mathrm{F}$ : Fischer's ratio 


\section{Thermal Analysis \\ FT-IR}

The samples of optimised CM microspheres and pure drug were used to compare the peaks observed by functional group diffraction using FTIR Instrument analysis. (Model used to analysis, BRUKER).

\section{Differential scanning calorimetry}

The pure drug and optimised formulation of CM microspheres was investigated for thermal analysis by using Shimmadzu DSC 60. Thermo grams results were in the heat rate from $0^{\circ} \mathrm{C}$ to $300^{\circ} \mathrm{C}$ with $10^{\circ} \mathrm{C} / \mathrm{min}$.

\section{X-Ray Diffraction Studies}

$\mathrm{X}$-ray diffraction study of pure drug and optimised formulation were verified by Jeol JDX 8030 X-ray diffractometer with definite amount samples with copper target at a voltage of $40 \mathrm{kV}$, current of $30 \mathrm{~mA}$. The scanning was carried through range of $5^{\circ}$ to $100^{\circ}$.

\section{Scanning electron microscope}

The optimised formulation of CM microsphere surface morphology was carried out by scanning electron microscopy (Model JSM 840 A, Jeol, Japan) was performed at $15 \mathrm{kV}$ with capacity current about $80 \mathrm{~mA}{ }^{23}$

\section{Ex vivo mucoadhesion studies}

The falling liquid film technique was followed for mucoadhesive property. $5 \mathrm{~cm}$ lengthy sheep nasal mucosa of freshly diced piece, acquired from a local abattoir inside $2 \mathrm{hr}$ of slaughter the animal was prepared by rinse with isotonic saline solution. Accurately weighed amount of microspheres were sprinkled on the nasal mucosa, which was attached over a glass slide. This glass slide was kept aside for $15 \mathrm{~min}$ in a desiccator at $90 \%$ relative humidity to permit the polymer complex of microspheres to interact with the membrane and then position of stand changed to 45 Degree angle. Previously heated $\left(37 \pm 0.5^{\circ} \mathrm{C}\right)$ Phosphate buffer $\mathrm{pH} 6.2$ was allowed to flow over the microspheres present in membrane with $(1 \mathrm{ml} / \mathrm{min}$ ) for $5 \mathrm{~min}$ using peristaltic pump (Kulkarni $\mathrm{AD}$ et al. 2016). The drug content concentration was determined HPLC method described in entrapment efficiency.

\section{Accelerated Stability Studies}

The stability testing microspheres with quality attributes drug product differs with age under the stress condition influence such as temperature, humidity and light as per the approved $\mathrm{ICH}$ guidelines. The optimized formulation was packed in amber colour glass vials and stored in a programmable environmental test chamber at $40^{\circ} \mathrm{C}$ and $75 \%$ RH for 6 months.

\section{RESULTS}

\section{The percentage yield}

CM microspheres observed yield of drug product were obtained between 62.51 to $74.45 \%$ Table 2. The product Yield was increased with the concentration of chitosan which have inert process parameters such as propeller speed and impact of lyophilisation complemented the yield value.

\section{Drug Entrapment efficiency}

$\mathrm{CM}$ microspheres were determined by centrifugation technique revealed moderate to high values of entrapment efficiency with range 69.5477.83 in all prepared microspheres. The entrapment efficiency shown synergetic effect by increase in concentration beta cyclodextrin with chitosan. There was no much influence of process parameters of design formulation.

\section{Drug diffusion studies}

The drug releases in all formulations were in $76.17 \%$ to $84.81 \%$ Table 2. This study was carried out by semipermeable membrane soaked overnight with nasal simulation fluid and study performed for $6 \mathrm{hr}$. The encapsulation property was enhanced in presence beta cyclodextrin, chitosan with lyophilisation effects release of clarithromycin was found significant from microspheres composite.

\section{Particle size and size distribution, Polydispersibility index}

The particle size, polydispersibility index of formulated microspheres was in targeted range of 12.25 to $16.03 \mu \mathrm{m}, 0.23$ to 0.76 were observed by Malvern Zetasizer.

\section{Zeta potential}

The surface potential of aqueous dispersed microspheres was observed between -15.34 to $-26.38 \mathrm{mV}$. The composite microsphere exhibited surface potential in presence of cationic chitosan polymer, beta cylcodextrin and formulated additive property state suitability for nasal application.

\section{Thermal Analysis \\ FT-IR}

Peaks of FTIR spectrum of CM and Optimised formulation shows 1628.23, 1068.77 and 1107.12, 2940.83 and 2972.34 and 3430.35 and 3492, which are attributed with $\mathrm{C}=\mathrm{O}$ From Keto Group, O- Ether, $-\mathrm{CH} 3$ (alkyl) and -OH Bond of CM. In optimised formulation observed no shift in the bands, Confirm no interaction of excipient used in formulation clarithromycin microspheres.

\section{Differential scanning calorimetry}

Differential scanning calorimetry of clarithromycin and optimised formulation were shown in Figure 2, endothermic peaks of $\mathrm{CM}$ pure drug were obtained at $112.33^{\circ} \mathrm{C}, 125.92^{\circ} \mathrm{C}$ and $223.90^{\circ} \mathrm{C}$. Optimised CM micropsheres spotted with less intensity of endothermic peak with only

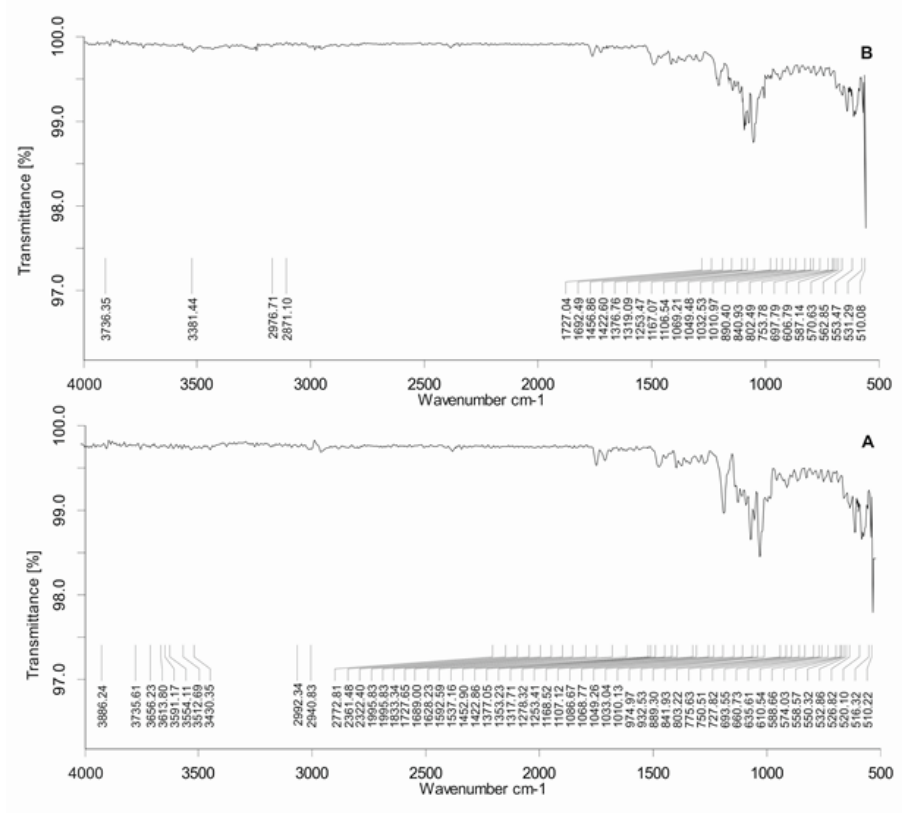

Figure 1: FTIR spectrum of A) Clarithromycin pure drug, B) Optimized formulation of CM Microspheres. 
peak at $218.16^{\circ} \mathrm{C}$ indicate that confirmation of inert property of polymer dispersions in presence of chitosan and beta cyclodextrin, absence of other two peak were the may be effect of polymer glass transition effect.

\section{X-Ray Diffraction Studies}

The crystallinity of clarithromycin in optimised formulation was tested with X-ray diffraction is shown in Figure 2, Clarithromycin has observedpeaks position ${ }^{\circ} 2$ theta at $8.60,9.54,10.93$ with relative intensity of $43.83 \%, 63.58 \%, 100.00 \%$ and intensity of peak height counts were 11666, 16922 and 26617. Similarly the optimised formulation obtained peaks at $8.94,9.44$ and 10.80 with relative intensity of $43.78 \%, 62.28 \%$, $87.68 \%$ and intensity of peak height counts were 3910,5563 and 7831 . This result suggested that same way of Clarithromycin peak results were observed between pure drug and optimised formulation, but intensity of peak was reduced height suggested the decreased crystallinity in prepared microspheres.

\section{Scanning electron microscope}

The SEM photomicrograph microspheres Figure 3 surface of CM pure drug observed with crystalline form with rod shape confirms the crystalline nature. Optimised formulation microsphere was spherical in nature with slightly rough in nature on the polymeric wall, state effect lyophilisation in formulation.

\section{Ex vivo mucoadhesion studies}

Mucoadhesion property of microspheres was in range of 77.54 to 88.54 $\%$ Table 2, determines the time lag for deposition in nasal mucosa with mucoadhesive property of chitosan, beta cyclodextrin in formulation.
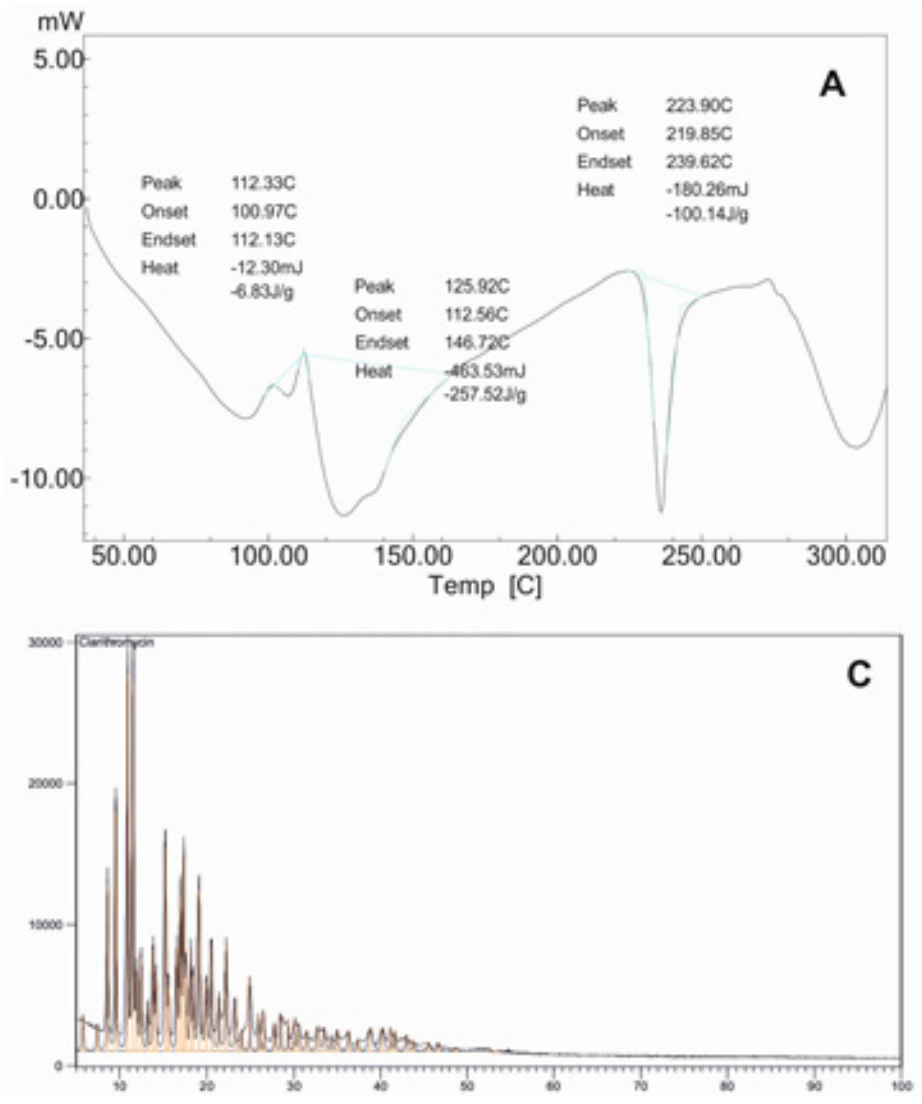

\section{Optimisation}

The runs or formulation are Two Level four factorial based designed which are evaluated for the response. The parameters in ANOVA were analysed for $R^{2}$ Value, Standard deviation, Coefficient of variation, Sum of squares, Degree of freedom, Mean sum of squares and Fischer's ratio.

\section{ANOVA}

All dependent variables ANOVA Table 1 was significant with linear model for all responses. $P$-values less than 0.0500 indicate model terms are significant. Hence from above result it indicates that the factors of materials and process variable play a vital role on the clarithromycin microsphere formulations.

\section{D Response surface plot}

Dependent variables of material factors chitosan and beta cylcodextrin, process factors propeller speed and lyophilisation temperature were analysed. Among these four factors for overall study results suggested effect of chitosan and propeller speed were found significant with positive effect. Graph results Figure 4 shown similarity in effect dependant on mostly chitosan followed by propeller speed when compare to other factors in particle Size, entrapment efficiency, mucoadhesion and maximum drug release.

\section{Accelerated Stability Studies}

The results of optimised formulation stability study shown in the Table 3, Determination of particle size was observed in the range of 14.23 to 14.16 indicate that no change with respect to aging of microspheres. The very minimal change was observed during this study of drug release, $\%$ entrapment efficiency and mucoadhesion. Therefore we can conclude that the optimised formulation is stable.
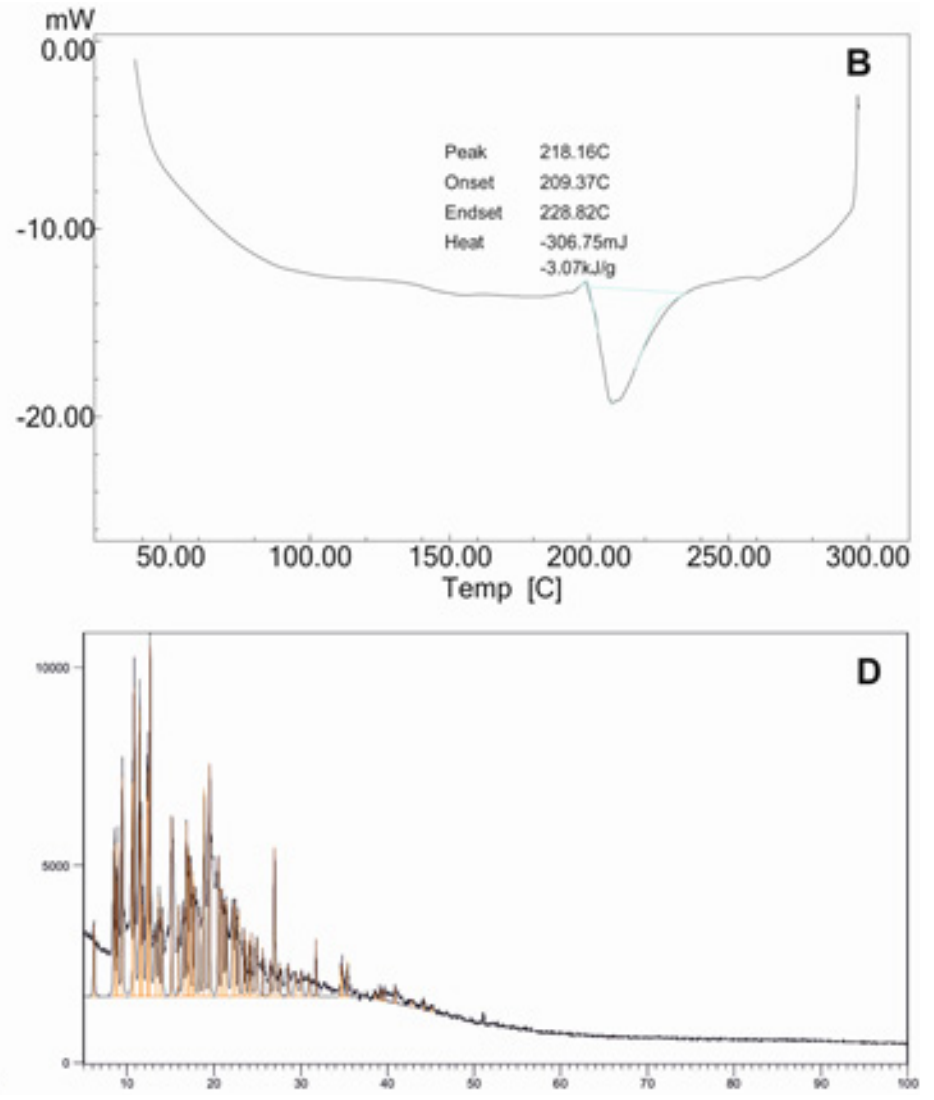

Figure 2: DSC Thermo grams and XRD of A and C) Clarithromycin pure drug, B and D) Optimized formulation of CM Microspheres. 
Table 2: Design Formula with coded value, characterisation of Clarithromycin microspherfes by factorial experimental model.

\begin{tabular}{|c|c|c|c|c|c|c|c|c|c|}
\hline 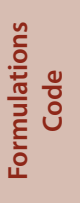 & 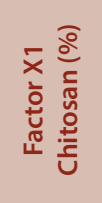 & 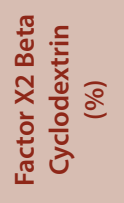 & 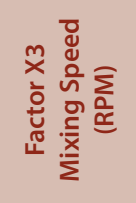 & 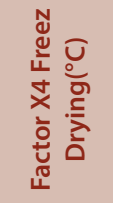 & 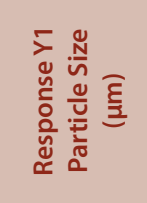 & 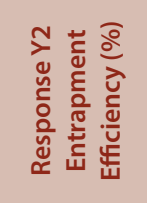 & 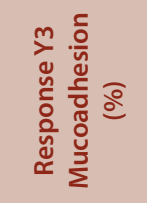 & 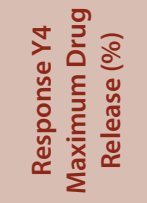 & 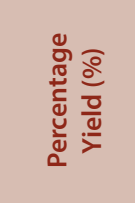 \\
\hline $\mathrm{F} 1$ & $1(+1)$ & $0.5(-1)$ & $6000(-1)$ & $100(+1)$ & $15.64 \pm 0.1$ & $74.56 \pm 0.35$ & $85.77 \pm 0.41$ & $82.28 \pm 0.22$ & $72.53 \pm 0.42$ \\
\hline F2 & $1(+1)$ & $1(+1)$ & $12000(+1)$ & $100(+1)$ & $14.94 \pm 0.09$ & $77.83 \pm 0.34$ & $88.54 \pm 0.46$ & $84.81 \pm 0.25$ & $74.45 \pm 0.43$ \\
\hline F3 & $1(+1)$ & $0.5(-1)$ & $12000(+1)$ & $40(-1)$ & $14.22 \pm 0.14$ & $76.33 \pm 0.31$ & $86.97 \pm 0.39$ & $84.17 \pm 0.28$ & $73.46 \pm 0.40$ \\
\hline F4 & $0.5(-1)$ & $1(+1)$ & $6000(-1)$ & $100(+1)$ & $13.85 \pm 0.16$ & $72.24 \pm 0.37$ & $77.54 \pm 0.42$ & $78.36 \pm 0.30$ & $64.27 \pm 0.33$ \\
\hline F5 & $0.5(-1)$ & $0.5(-1)$ & $12000(+1)$ & $100(+1)$ & $12.25 \pm 0.11$ & $70.45 \pm 0.40$ & $74.52 \pm 0.46$ & $78.15 \pm 0.34$ & $66.22 \pm 0.35$ \\
\hline F6 & $0.75(0)$ & $0.75(0)$ & $9000(0)$ & $70(0)$ & $14.35 \pm 0.21$ & $74.41 \pm 0.43$ & $83.35 \pm 0.40$ & $80.53 \pm 0.35$ & $70.27 \pm 0.36$ \\
\hline F7 & $1(+1)$ & $1(+1)$ & $6000(-1)$ & $40(-1)$ & $16.03 \pm 0.14$ & $76.21 \pm 0.29$ & $87.68 \pm 0.38$ & $83.94 \pm 0.29$ & $73.64 \pm 0.38$ \\
\hline F8 & $0.5(-1)$ & $1(+1)$ & $12000(+1)$ & $40(-1)$ & $13.06 \pm 0.12$ & $73.14 \pm 0.46$ & $78.12 \pm 0.51$ & $80.55 \pm 0.45$ & $67.13 \pm 0.45$ \\
\hline F9 & $0.5(-1)$ & $0.5(-1)$ & $6000(-1)$ & $40(-1)$ & $13.31 \pm 0.16$ & $69.54 \pm 0.45$ & $73.58 \pm 0.53$ & $76.17 \pm 0.47$ & $62.51 \pm 0.47$ \\
\hline
\end{tabular}

Table 3: Stability Study parameters.

\begin{tabular}{ccccc}
$\begin{array}{c}\text { Time } \\
\text { in } \\
\text { Month }\end{array}$ & $\begin{array}{c}\text { Particle } \\
\text { Size }(\mu \mathrm{m})\end{array}$ & $\begin{array}{c}\text { Entrapment } \\
\text { Efficiency }(\%)\end{array}$ & $\begin{array}{c}\text { Mucoadhesion } \\
(\%)\end{array}$ & $\begin{array}{c}\text { Maximun } \\
\text { Drug Release } \\
(\%)\end{array}$ \\
\hline Initial & $14.23 \pm 0.15$ & $73.68 \pm 0.25$ & $81.56 \pm 0.41$ & $81.04 \pm 0.35$ \\
One & $14.23 \pm 0.19$ & $73.66 \pm 0.31$ & $81.57 \pm 0.38$ & $81.06 \pm 0.37$ \\
Three & $14.20 \pm 0.21$ & $73.65 \pm 0.38$ & $81.50 \pm 0.39$ & $80.86 \pm 0.42$ \\
Six & $14.16 \pm 0.27$ & $73.62 \pm 0.35$ & $81.48 \pm 0.40$ & $80.75 \pm 0.44$ \\
\hline
\end{tabular}

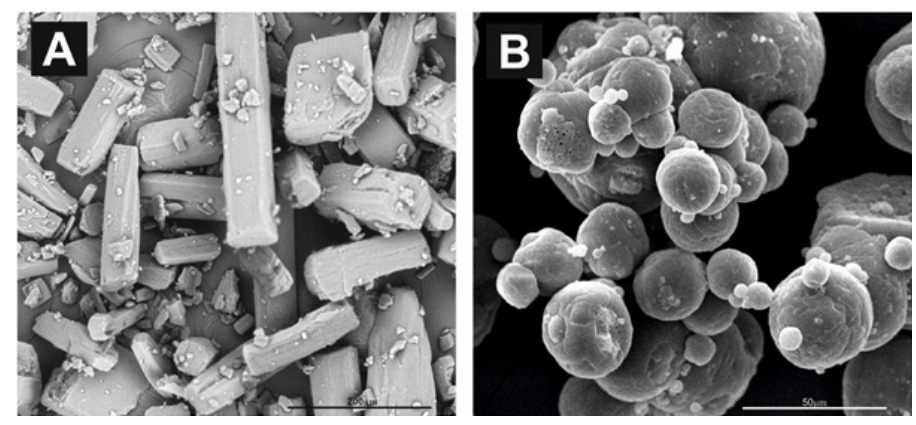

Figure 3: A) Clarithromycin pure drug \& B) Optimized formulation of CM Microspheres

\section{DISSCUSSION}

This current study performed to design, development of chitosan beta cyclodextrin based nasal mucoadhesive microspheres of clarithromycin for an alternative dosage form as novel formulation with improved physicochemical characters, to exhibit effective utilisation for respiratory tract infections. In the recent advances nasal formulation, potential auxiliary agents of permeation enhancing agents, mucolytic agents, mucoadhesive agents, in situ gelling agents and enzyme inhibiting agents significantly improved the product quality. ${ }^{24}$ To clarify materials, process and methods of in vitro and ex vivo test measure in effectiveness and acceptance of a novel drug-delivery system. ${ }^{25}$

Yield value of drug formulation reflected in increase of drug-to-polymer ratio with minimum mixing speed, minimum lyophilisation efficiency process found to be satisfactory to obtain the target quality attribute of formulations. The effect of prepared microspheres on entrapment efficiency is similar process effect as in product yield. Entrapment efficiency may be influence of crosslinking agent and excipients used in this formulation design of experiment as reported. ${ }^{26}$

In all formulations depend on polymer concentration ratio, CM release was increases when increase in concentration of chitosan and beta cyclodextrin as synergic effect. Here beta cyclodextrin complement chitosan to hydrating and enhance crystalline drug release better. The release kinetic model of optimised formulation was best fit to Korsmeyer-Peppas model than higuchi model, then zero order kinetic and first order kinetic equation. This observed result were suggested similarity in maximum drug release effect as mentioned in optimized nasal mucoadhesive micropsheres of lercanidipine. ${ }^{26}$

IR Spectral interpretation results indicate that no drug - polymer interaction in the formulated optimised microspheres to drug and they are compatible Figure 3. Optimised formulation microspheres results indicating with targeted particle size, minimum ploy-dispersibility index and slightly anionic nature of surface property were noted. Surface structure revealed spherical shape and surface of microsphere seen the drug is completely encapsulated with polymer matrix shell. The experiential particle size in micron ranged pattern with good uniform characteristics.

The optimised formulation microsphere of DSC study infers that drug is completely dispersed in the polymer matrix. XRD study also states that intensity of peaks of diffraction was found high in CM when compared to the optimized formulation which indicating the reduction of crystallinity or complete dispersion of CM microsphere as mentioned earlier report. ${ }^{27}$ The surface morphology of prepared microspheres by emulsification indicate good spherical in nature was observed and signify possibility of improved drug release from microspheres as reported Characteristics of APS/CTS microspheres. ${ }^{28}$ The result of ANOVA in Table 1 proves that the model was significant. Regression analysis was performed to limit the regression coefficients. All the four independent variables in the model were found significant. So, above result indicate that the factors play an important role in the formulation of microspheres containing clarithromycin with material and process parameters. By this optimization factorial design model consist of material and process parameters as variable with responses, it was observed that desirability conclusive report accordingly with control strategic parameters was suggested that optimised formulation of predicted values were with chitosan 0.604, Beta cylclodextrin 0.7633, Propeller Mixing Speed 9369 and Lyocycle temperatue of $-42.8^{\circ} \mathrm{C}$. Accelerated stability studies of microspheres were not observed any change in physical appearance 

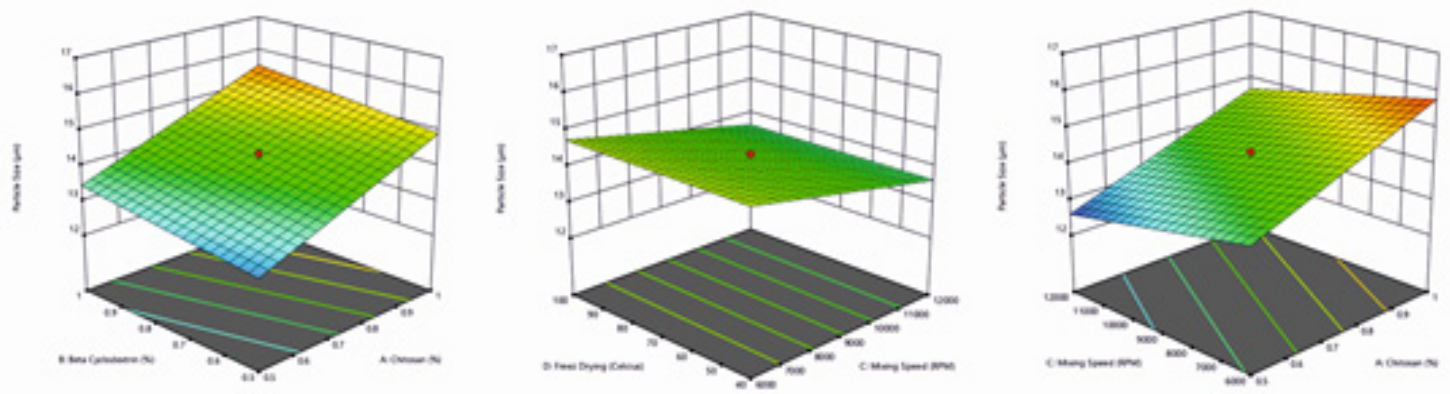

3D Surface Graph Influence of Variables of Particle Size
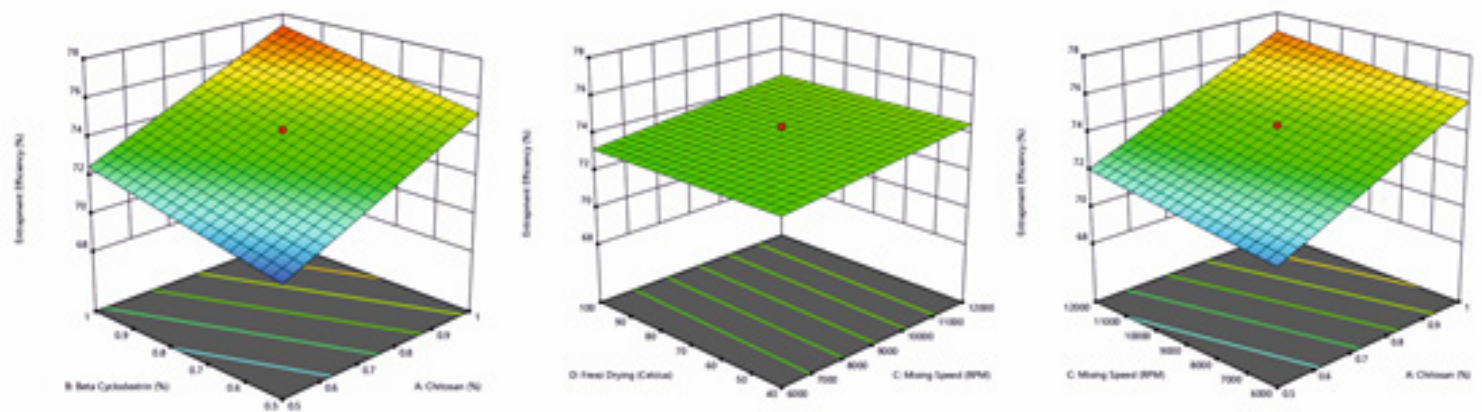

3D Surface Graph Influence of Variables of Entrapment Efficiency
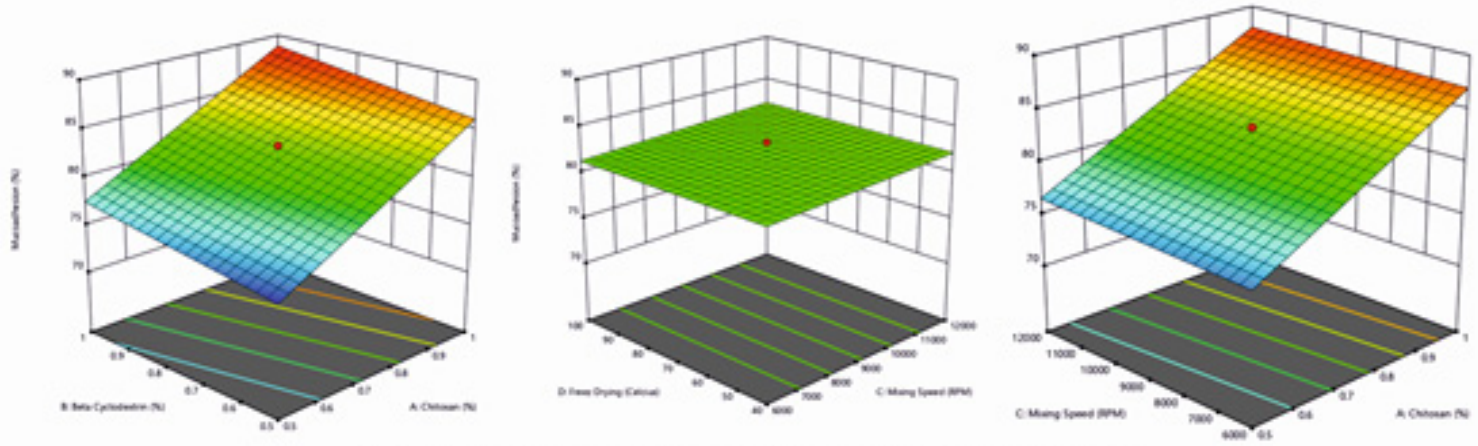

3D Surface Graph Influence of Variables of Mucoadhesion
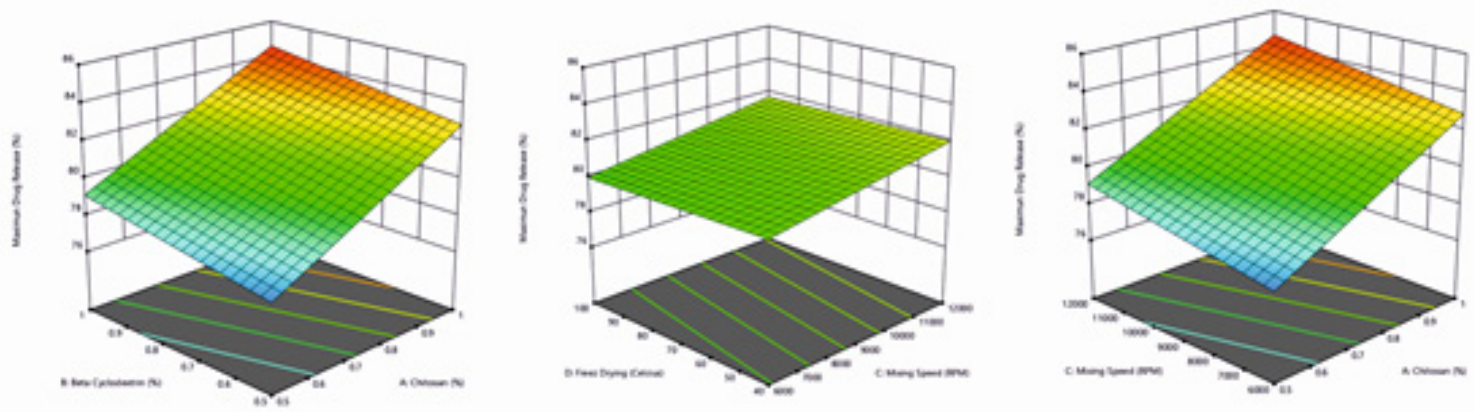

3D Surface Graph Influence of Variables of Maximum Drug Release

Figure 4: Clarithromycin microsphere Optimisation 3D graphs.

and its evaluation parameters indicate robustness of this formulation for further process development.

\section{CONCLUSION}

From this research work, it can be concluded that clarithromycin nasal mucoadhesive microspheres were feasible to prepare by modified emulsion-lyophilisation technique. Experiment results suggested that, Nasal microspheres of CM with Chitosan, $\beta C D$ were identical. FTIR results were found no interaction between polymers and drug; they are compatible with each other. Particle size, PDI and Zeta potential of microspheres was within the range. Mucoadhesion, drug release and entrapment efficiency were found to be fairly acceptable with standards. 
SEM studies indicate surface topography having spherical and slight rough surface in formulation, DSC and XRD were recorded to see the drug status. Stability studies revealed that optimized formulation was stable. Finally it was concluded that the prepared nasal microspheres of clarithromycin may prove to be potential enough for effective drug delivery.

\section{ACKNOWLEDGEMENT}

The author is grateful to the Department of Pharmaceutical Technology, Annamalai University, Tamil Nadu and Karnataka College of Pharmacy, Bengaluru, India, for their complete support and useful guidance.

\section{CONFLICT OF INTEREST}

The authors declare none.

\section{ABBREVIATIONS}

CM: Clarithromycin; $\boldsymbol{\beta C D}$ : Beta Cyclodextrin; FTIR: Fourier Transform Infrared Spectroscopy; PDI: Polydispersibility Index; DSC: Diffrential Scanning Calorimetry; XRD: X-Ray Diffraction; SEM: Scanning electron microscope; ICH: International Conference on Harmonisation; HPLC: High performance liquid chromatography.

\section{REFERENCES}

1. Illum L. Nasal drug delivery-possibilities, problems and solutions. J Control Release. 2003;87(1):187-98. doi:https://doi.org/10.1016/S0168-3659(02)00363-2

2. Ugwoke MI, Agu RU, Verbeke N, Kinget R. Nasal mucoadhesive drug delivery: Background, applications, trends and future perspectives. Adv Drug Deliv Rev. 2005;57(11):1640-65. doi:10.1016/j.addr.2005.07.009

3. Alpar HO, Somavarapu S, Atuah KN, Bramwell WW. Biodegradable mucoadhesive particulates for nasal and pulmonary antigen and DNA delivery. Adv Drug Deliv Rev. 2005;57(3):411-30. doi:10.1016/j.addr.2004.09.004

4. Issa MM, Köping-Höggård M, Artursson P. Chitosan and the mucosal delivery of biotechnology drugs. Drug Discov Today Technol. 2005;2(1):1-6. doi:https://doi. org/10.1016/j.ddtec.2005.05.008

5. Leitner VM, Guggi D, Krauland AH, Bernkop-Schnürch A. Nasal delivery of human growth hormone: In vitro and in vivo evaluation of a thiomer/glutathione microparticulate delivery system. J Control Release. 2004;100(1):87-95. doi:https://doi.org/10.1016/j.jconrel.2004.08.001

6. Patil SB, Sawant KK. Development, optimization and in vitro evaluation of alginate mucoadhesive microspheres of carvedilol for nasal delivery. J Microencapsul. 2009;26(5):432-43. doi:10.1080/02652040802456726

7. Nižić L, Potaś J, Winnicka K et al. Development, characterisation and nasal deposition of melatonin-loaded pectin/hypromellose microspheres. Eur J Pharm Sci. 2020;141:105115. doi:https://doi.org/10.1016/j.ejps.2019.105115

8. Kulkarni $A D$, Bari DB, Surana SJ, Pardeshi CV. In vitro, ex vivo and in vivo performance of chitosan-based spray-dried nasal mucoadhesive microspheres of diltiazem hydrochloride. J Drug Deliv SciTechnol. 2016;31:108-17. doi:https://doi. org/10.1016/j.jddst.2015.12.004

9. Brzeziński M, Kost B, Wedepohl S, Socka M, Biela T, Calderón M. Stereocomplexed PLA microspheres: Control over morphology, drug encapsulation and anticancer activity. Colloids Surfaces B Biointerfaces. 2019;184:110544. doi:https://doi.org/10.1016/j.colsurfb.2019.110544

10. Sun Y, Shi K, Wan F, Cui F. Methotrexate-loaded microspheres for nose to brain delivery: In vitro/in vivo evaluation. J Drug Deliv Sci Technol. 2012;22(2):167-74.
doi:https://doi.org/10.1016/S1773-2247(12)50022-5

11. Fine JM, Forsberg AC, Renner $\mathrm{DB}$, et al. Intranasally-administered deferoxamine mitigates toxicity of 6-OHDA in a rat model of Parkinson's disease. Brain Res. 2014;1574:96-104. doi:https://doi.org/10.1016/j.brainres.2014.05.048

12. Reed KD. Chapter 84 - Respiratory Tract Infections: A Clinical Approach Schwartzman JBT-MMM (Second E, eds. Academic Press. 2015:1499-506. doi:https://doi.org/10.1016/B978-0-12-397169-2.00084-6

13. Soisuwan S, Teeranachaideekul V, Wongrakpanich A, Langguth $P$, Junyaprasert VB. Impact of uncharged and charged stabilizers on in vitro drug performances of clarithromycin nanocrystals. Eur J Pharm Biopharm. 2019;137:68-76. doi:https://doi.org/10.1016/j.ejpb.2019.02.004

14. Manniello MD, DelGaudio P, Aquino RP, Russo P. Clarithromycin and N-acetylcysteine co-spray-dried powders for pulmonary drug delivery: A focus on drug solubility. Int J Pharm. 2017;533(2):463-9. doi:https://doi.org/10.1016/j. ijpharm.2017.03.079

15. Karmoker JR, Hasan I, Ahmed N, Saifuddin M, Reza M. Development and Optimization of Acyclovir Loaded Mucoadhesive Microspheres by Box -Behnken Design. Dhaka Univ J Pharm Sci. 2019;18(1):1-2. doi:10.3329/dujps.v18i1.41421

16. Kyada C, Ranch K, Shah D. Optimization of mucoadhesive microspheres of acyclovir by applying 32 full factorial design. J Drug Deliv SciTechnol. 2014;24(1):618. doi:10.1016/S1773-2247(14)50009-3

17. Patel S, Koradia H, Parikh R. Design and development of intranasal in situ gelling system of Midazolam hydrochloride using 32 full factorial design. J Drug Deliv Sci Technol. 2015;30:154-62. doi:10.1016/j.jddst.2015.10.010

18. Shah S, Gohil D, Pandya D, Meshram D. Preparation and evaluation of spraydried mucoadhesive microspheres for intranasal delivery of prochlorperazine using factorial design. Asian J Pharm. 2015;9(3):178-89. doi:10.4103/09738398.160314

19. Kristin F, René H, Boontida M, et al. Dissolution and dissolution/permeation experiments for predicting systemic exposure following oral administration of the BCS class II drug clarithromycin. Eur J Pharm Sci. 2017;101:211-9. doi:10.1016/j. ejps.2017.02.003

20. Soisuwan S, Teeranachaideekul V, Wongrakpanich A, Langguth $P$, Junyaprasert VB. In vitro performances and cellular uptake of clarithromycin nanocrystals produced by media milling technique. Powder Technol. 2018;338:471-80. doi:https://doi.org/10.1016/j.powtec.2018.07.036

21. Yang M, Cui F, You B, et al. Preparation of sustained-release nitrendipine microspheres with Eudragit RS and Aerosil using quasi-emulsion solvent diffusion method. Int J Pharm. 2003;259(1-2):103-13. doi:10.1016/S0378-5173(03)002096

22. Rajawat GS, Shinde UA, Nair HA. Chitosan-N-acetyl cysteine microspheres for ocular delivery of acyclovir: Synthesis and in vitro/in vivo evaluation. J Drug Deliv Sci Technol. 2016;35:333-42. doi:https://doi.org/10.1016/j.jddst.2016.08.006

23. Pokharkar VB, Jolly MR, Kumbhar DD. Engineering of a hybrid polymer-lipid nanocarrier for the nasal delivery of tenofovir disoproxil fumarate: Physicochemical, molecular, microstructural and stability evaluation. Eur J Pharm Sci. 2015;71:99-111. doi:10.1016/j.ejps.2015.02.009

24. Rohrer J, Lupo N, Bernkop-Schnürch A. Advanced formulations for intranasal delivery of biologics. Int J Pharm. 2018;553(1-2):8-20. doi:10.1016/J. IJPHARM.2018.10.029

25. Salade L, Wauthoz N, Goole J, Amighi K. How to characterize a nasal product: The state of the art of in vitro and ex vivo specific methods. Int J Pharm. 2019;561:47-65. doi:10.1016/J.IJPHARM.2019.02.026

26. Beg S, Rahman M, Panda SK, et al. Nasal Mucoadhesive Microspheres of Lercanidipine with Improved Systemic Bioavailability and Antihypertensive Activity. J Pharm Innov. 2020. doi:10.1007/s12247-020-09441-5

27. Soisuwan $S$, Teeranachaideekul V, Wongrakpanich $A$, Langguth $P$, Junyaprasert VB. Impact of uncharged and charged stabilizers on in vitro drug performances of clarithromycin nanocrystals. Eur J Pharm Biopharm. 2019:137(November 2018):68-76. doi:10.1016/j.ejpb.2019.02.004

28. Wang S, SunY, Zhang J, et al. Astragalus Polysaccharides/Chitosan Microspheres for Nasal Delivery: Preparation, Optimization, Characterization and Pharmacodynamics. Front Pharmacol. 2020;11:230. doi:10.3389/fphar.2020.00230

Article History: Submission Date : 24-07-2020; Revised Date : 20-08-2020; Acceptance Date : 15-09-2020.

Cite this article: Rajarajan S, Prakash BR, Selvamuthukumar S. Design and Development of Chitosan Beta-cyclodextrin based Nasal Mucoadhesive Microspheres of Clarithromycin. Int. J. Pharm. Investigation, 2020;10(3):279-85 